\title{
Reform and Practice of "Fundamentals of Environmental Chemistry" Teaching Contents Based on OBE Concept
}

\author{
Xiangyang $\mathrm{Wu}^{1, \mathrm{a}}$, Zhixiang $\mathrm{Han}^{1, \mathrm{~b}}$, Zhen Zhang ${ }^{1, \mathrm{c}}$, Guoxi Liang $^{1, \mathrm{~d}}$, and Xing Dong ${ }^{1, \mathrm{e}}$ \\ ${ }^{1}$ School of the environment and safety engineering, Jiangsu University, Zhenjiang 212013, China

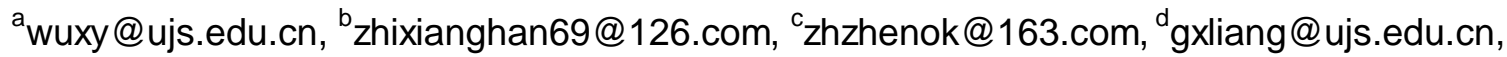 \\ exingd1982@163.com
}

Keywords: Environmental protection equipment engineering; Fundamentals of Environmental Chemistry; teaching reform; OBE concept

Abstract. Environmental protection equipment engineering is a new undergraduate major set up by the Ministry of Education of the People's Republic of China in 2010. "Fundamentals of Environmental Chemistry" is one of the discipline basic courses for the major. According to the professional talent training objectives, this article presents the necessity and importance of opening the course, the construction of the theoretical and experimental teaching contents system based on the OBE concept, and the good results of the reform and practice.

\section{Introduction}

Environmental protection industry is one of the China's strategic new industries and a bulk of talents are needed. For this reason, environmental protection equipment engineering undergraduate major was set up in the special catalogue by the Ministry of Education of the People's Republic of China in 2010, and officially enrolled new student in September of 2011. The training objectives of this major is to develop moral, intellectual, physical, and aesthetic development of people, to train top-ranking engineering technicians who have the concept of sustainable development, grasp the basic theory, knowledge and techniques on both environment engineering and mechanical engineering, possess the ability of research, development, design, manufacturing, installation, operation and management of environmental protection equipment in environment pollution control and the related fields.

As one of the first four universities approved by the Ministry of Education to set up this major, a series of teaching reforms were carried out since $2010^{[1-5]}$. According to the needs of the professional knowledge of chemistry, the contents of inorganic chemistry, organic chemistry, analytical chemistry, physical chemistry and environmental chemistry were optimized and integrated into "Fundamentals of Environmental Chemistry" with the guidance of Outcome-Based Education (OBE) concept ${ }^{[6,7]}$. And reform and practice of the theoretical and experimental teaching contents of the course was carried out with good results.

\section{The Importance and Necessity of Opening Fundamentals of Environmental Chemistry}

The basic knowledge, theory and experimental skills of chemistry are the basic scientific knowledge that should be mastered by environmental protection equipment engineering professionals and will make necessarily foundation for the next study of environmental analysis and test, water/air pollution control engineering and equipment and so forth. However, the theoretical and experimental teaching contents of chemistry are large and complicated. If we set up Four Chemistry (inorganic, organic, analytical and physical chemistry) and environmental chemistry and their corresponding experiments, the total class hours will reach more than 270. It's impractical and no need for the major. To solve this problem, a new curriculum "Fundamentals of Environmental Chemistry" was tested to set up after optimizing and integrating basic chemical knowledge, theory and experimental skills based on OBE concept. 


\section{Reform and Practice of Theoretical Teaching Contents}

\subsection{Optimize and integrate the basic knowledge of chemistry and construct the theoretical teaching system of the course.}

Currently, many problems exist in the original four chemistry (inorganic chemistry, organic chemistry, analytical chemistry, physical chemistry), such as the contents falling behind the times or overlap, illogicality, lack of relevance and coordination with major courses. To solve this problem, a new teaching contents system was constructed by optimization and integration the basic knowledge of chemistry. There are fourteen chapters in the theory contents of "Fundamentals of Environmental Chemistry" and list as following: 1. Basics of structural chemistry; 2. Gas, solution and colloids; 3. Thermochemistry and thermodynamics; 4. Acid-base equilibria \& Acid-base titration; 5. Precipitation-dissolution equilibria \& Precipitation titration; 6. Oxidation-reduction equilibria \& Oxidation-reduction titration; 7. Complex equilibria \& complex titration; 8. Absorption photometry \& potentiometry; 9. Classification, nomenclature, and the main properties of typical organic compounds; 10. Environmental pollutants \& environmental effects; 11. Atmospheric environmental chemistry; 12. Water environmental chemistry; 13. Soil environmental chemistry; 14. Biological assessment and ecological effects of environmental pollutions. From above, one can see that: 1 . the new course "Fundamentals of Environmental Chemistry" contains both the main contents of Four Chemistry and environmental chemistry; 2. Physical chemistry is selected as the forerunner and brought into full play the theoretical base of chemical subject; 3. Taking the Four Chemistry and environmental chemistry as a whole can break down barriers, avoid isolation, repetition and logical error, and enforce their interrelation.

\subsection{Actively introduce PBL and CBL teaching and integrate various teaching methods.}

Due to excessive and abstract contents of chemistry, it's difficult to achieve better teaching and learning quality by means of traditional teaching method (such as text-only or traditional forms of printed or hand-produced material). Multimedia assisted teaching is a modern teaching means which uses a combination of different content forms such as text, audio, images, animations, video and interactive content. Multimedia technique was applied in teaching the obscure principles of chemistry, the teaching will be lifesome and amusive, the experimental phenomenon will be intuitionist, and the students will easily understand.

In the process of teaching, we attempt to adopt the students-centered approach instead of the traditional teacher-centered approach and introduce the combination of "enlightened, investigated, questioned and discussed" teaching methods instead of "accepted learning” ones. Problem-based learning (PBL) ${ }^{[8]}$ and case-based learning (CBL) ${ }^{[9]}$ are also introduced and founded to be helpful in improving the teaching efficiency and the class atmosphere, in stimulating students learning enthusiasm and in attracting their attention, in comprehensively promotion students' abilities of analyzing and solving problems, in improvement of interpersonal communication skill and good team spirit.

For example, buffer solution in acid-base equilibria is a key and abstract knowledge point. To make clear of this point, we firstly introduce the concept and calculation formula of buffer solution, then hold a discussion on "weak alkalinity water is beneficial for human health or not" among the students, further bring in "the relationship between $\mathrm{pH}$ values of human and health", finally the related contents of "the evening party on march 15 ” was watched.

The choice of typical and representative environmental pollution cases is considered both early occurrences and recent events, domestic and foreign. For example, not only the four pollution affairs in Japan, Seveso's Chemical pollution events in Italy, the Bhopal disaster in Indian and the oil spill in the Gulf of Mexico in 2010 which all happened in foreign are selected, but also benzene homologues pollution in Songhua River in 2005, arsenic pollution in Yangzonghai lake in 2008, phenol pollution of water supplies in Zhenjiang in 2012 which all happened in China are also selected. Through these case studies, the sense of identity to the importance of majors and social responsibilities were strengthened. 


\section{Reform and Practice of Experimental Teaching Contents}

\subsection{Integrate the main experimental contents of chemistry and construct the experimental teaching contents system of the course.}

Integrated course can break the boundary of subjects, resolve subject standard and the lack of integration problem. After completely studying the experiment items of Four Chemistry and environmental chemistry, a new framework for the experiments of "Fundamental Environmental Chemistry" was built, which has the distinctive feature of the major. The items list as following: 1 . Introduction, 2 . The use of electronic analytical balance and the preparation of solution; 3. The determination of chemical reaction rate constant; 4. Preparation and calibration of the standard solution of hydrochloric acid; 5. Preparation and calibration of the standard solution of EDTA and its application in the determination of calcium and magnesium in tap water; 6. Preparation and calibration of the standard solution of potassium permanganate $\left(\mathrm{KMnO}_{4}\right) ; 7$. Determination of glucose in medicinal glucose injection by indirect iodometry; 8. Determination of Iron contents by 1,10-phenanthroline spectrophotometric colorimetry; 9. Indexes of self-purification degree in real water samples; 10 . The evaluation of water eutrophication. From the items, one can see that the experiments which train the similar skills are centrally scheduled and intensively trained. The arrangement will help students deepen their understanding and improve their proficiency in operational skills.

\subsection{Focus on the effectiveness of the experimental process and scientifically evaluate students' learning effects}

Preparation before experiment is very important for improvement the quality of experiment teaching. So detailed prelab report with clear experimental purpose, exact experimental principle, detailed operation steps and attentions is needed and no prelab report will be refused to take part in the experiment.

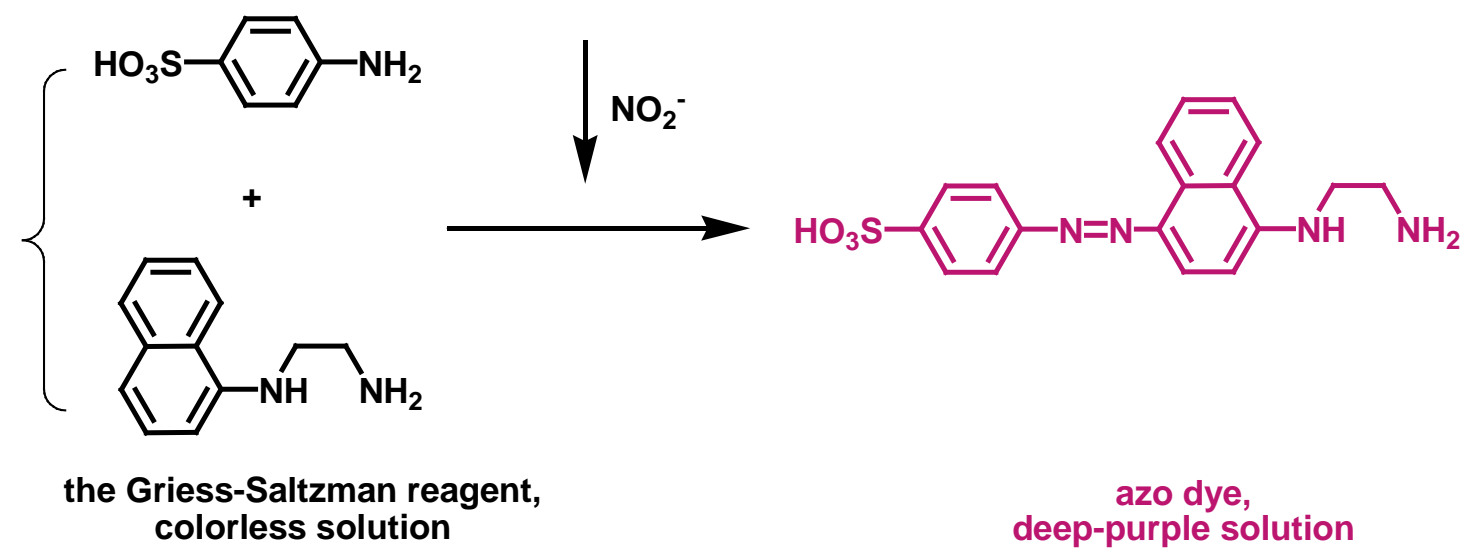

Fig. 1 Scheme of the Griess-Saltzman reaction.

Throughout the experiments, the ability of knowing not only what but also why was focused. For example, experiment 9 covers the contents of organic chemistry, analytical chemistry and environmental chemistry. However, most of students are lack of the knowledge of organic chemistry. To solve this problem, the detection principle (i.e. Griess-Saltzman reaction) is emphasized to explain (Fig. 1). As can see from Fig. 1, nitrite ions $\left(\mathrm{NO}_{2}^{-}\right)$in water solution can react with sulfanilic acid forming a diazonium salt, which further reacts with the naphthylamine component forming the azo dy $\mathrm{e}^{[10,11]}$. The solution color changes from colorless to deep purple. To deepen the students' understanding, two examples of the colored azo dyes including acid-base indicator methyl orange and the dreaded industrial dye Sudan red I are further introduced.

Scientific teaching evaluation method is set up to comprehensively check studying qualities of the students. Attendance accounts for $10 \%$, prelab report, performance of answering questions in course accounts for $10 \%$, operation accounts for 30\%, and the quality of experimental report (especially data processing) accounts for $50 \%$. This new evaluation method can stimulate students' learning interests, improve their learning initiative and their proficiency of basic operation skills and will be benefit to study the following course for students. 
The ability of data processing by the aid of computer for students is also emphasized. For example, commercial software origin, sigmaplot and excel are all introduced and applied to obtain the standard curve and regression equation of spectrophotometric colorimetry.

\section{Summary}

With seven years efforts, the teaching contents of the "Fundamentals of Environmental Chemistry" have been continuously improved and better teaching results also have been acquired. The reform and practice have been fully affirmed by the majority of students who having taken this course and insure the quality of talent training of environmental protection equipment engineering.

\section{Acknowledgment}

We thank the Key Projects of Higher Education Teaching Reform in Jiangsu University in 2017 "Research and Practice on the Construction of the Course System of Environmental Chemistry Based on OBE Concept" for financially support (No. 2017021).

\section{References}

[1]. H. Liu, X. Y. Wu, C. W. Yi. Practice and exploration on the construction of environmental engineering major in Jiangsu University [J]. Education and Vocation, 2010, vol. 35, pp 125-127. (In Chinese).

[2]. Q. J. Xie, R. J. Zhao, H. Liu, J. Y. Chu. The construction of environmental protection equipment engineering inter-disciplinary talents training program in Jiangsu University [J]. China Electric Power Education, 2012, vol. 32, pp 29-30. (In Chinese).

[3]. Q. J. Xie, X. Y. Wu, R. J. Zhao, C. G. Shen. The ponder about curriculum set-up and textbook build of environmental protection equipment engineering major [J]. China Electric Power Education, 2013, vol. 34, pp 103-106. (In Chinese).

[4]. Q. Li, X. Y. Wu, H. Liu, Q. J. Xie. Practice and ponder about curriculum construction of "water pollution and control engineering” for environmental protection equipment engineering major [J]. Education Science, 2016, vol. 1, pp 262-262. (In Chinese).

[5]. Q. J. Xie, X. Y. Wu, H. Liu, C. W. Yi, R. J. Zhao. Construction and research of the practical teaching system for environmental protection equipment engineering major [J]. University Education, 2017, vol. 4, pp 50-52. (In Chinese).

[6]. W. D. Spady. Outcome-Based Education: Critical Issues and Answers. Arlington Virginia: American Association of School Administrators. 1994.

[7]. P. H. Gu, W. L. Hu, P. Lin, N. S. Bao, X. H. Lu, G. J. Xiong, Y. Chen. OBE engineering education model in Shantou University [J]. Higher Engineering Education Research, 2014, vol. 1, pp. 27-37. (In Chinese).

[8]. H. S. Barrows. Problem-based learning in medicine and beyond: A brief overview. New Directions for Teaching and Learning. 1996, vol. 68, pp. 3-12.

[9]. C. A. F. Rosenstand. Case-Based Learning. In: Seel N.M. (Eds) Encyclopedia of the Sciences of Learning. Springer, Boston, MA. 2012.

[10]. B. E. Saltzman. Colorimetric microdetermination of nitrogen dioxide in atmosphere. Analytical Chemistry, 1954, vol. 26, pp 1949-1955. 
[11]. C. Fàbrega, L. Fernández, O. Monereo, A. Pons-Balagué, E. Xuriguera, O. Casals, A. Waag, and J. D. Prades. Highly specific and wide range $\mathrm{NO}_{2}$ sensor with color readout [J]. ACS Sensors, 2017, vol. 2, pp 1612-1618. 